\title{
Petrophysical Reservoir Characterization of Habiganj Gas Field, Surma Basin, Bangladesh
}

\author{
Shamiha Shafinaz Shreya ${ }^{1}$, Md. Anwar Hossain Bhuiyan ${ }^{1}$, Shakhawat Hossain ${ }^{1}$ and Tania Sultana ${ }^{2}$ \\ ${ }^{1}$ University of Dhaka, Dhaka, Bangladesh \\ ${ }^{2}$ Reservoir and Data Management Division, Petrobangla, Dhaka, Bangladesh
}

Manuscript received: 25 April 2021; accepted for publication: 27 August 2021

\begin{abstract}
The previous studies on the petrophysical and volumetric analysis of Habiganj gas field were based on limited well data. As the accuracy of volumetric analysis relies greatly on petrophysical parameters, it is important to estimate them accurately. In this study we analyzed all eleven wells drilled in the Habiganj field to determine the petrophysical parameters. Analysis of the well logs revealed two distinct reservoir zones in this field termed as upper reservoir zone and lower reservoir zone. Stratigraphically, these two reservoir zones are in the Bokabil and Bhuban Formation of Surma Group. Petrophysical analysis shows significant differences between the two zones in terms of petrophysical parameters. Porosity in the upper reservoir zone ranges from $12 \%$ to $36 \%$, with an average of $28 \%$. This zone is highly permeable, as indicated by the average permeability of 500 mili Darcy $(\mathrm{mD})$. The average water saturation in this zone is around $18 \%$ suggesting high gas saturation. The lower reservoir zone has an average porosity, permeability, and water saturation of $12 \%, 60 \mathrm{mD}$, and $43 \%$, respectively, indicating poor reservoir quality. An analysis of log motifs indicates that the upper reservoir zone is composed of stacked sands of blocky pattern. The sands in this interval are clean, as indicated by the lower shale volume of $12-15 \%$. The average thickness of this zone is $230 \mathrm{~m}$, and the presence of this zone in all the drilled wells suggests high lateral continuity. The lower reservoir zone consists of sand bodies of serrated pattern. The sands have high shale volume and are laterally discontinuous. Overall, the upper reservoir zone has superior petrophysical properties to the lower reservoir zone. Although the reservoir quality of the lower reservoir zone is poorer than that of the upper zone, this zone can be considered as the secondary target for hydrocarbon production. Petrophysical parameters of this study were estimated from all the eleven wells drilled in this field; hence the values are more accurate. The reported values of the petrophysical parameters in this study are recommended to use to re-estimate the reserves in Habiganj field.
\end{abstract}

Keywords: Petrophysical analysis, Reservoir, Well logs, Habiganj gas field, Surma basin

\section{INTRODUCTION}

Bangladesh is standing at a critical stage in terms of natural gas reserves. It is necessary to reassess the available resources to comprehend the gravity of this situation. At this stage, efforts to maximize hydrocarbon production from mature hydrocarbon fields like Habiganj Gas Field are much dependent on geological reservoir characterization.

The geological characterization of reservoirs requires full utilization of all types of data from the subsurface. These data may include geophysical well $\operatorname{logs}$, core analyses, mud $\operatorname{logs}$, production histories, drill-stem, and other test data, pressure data, and injection profiles. A physical framework for the reservoir is defined by the most abundant data (invariably well logs), and cores are carefully

Corresponding author: Md. Anwar Hossain Bhuiyan

Email: ahb@du.ac.bd

DOI: https://doi.org/10.3329/dujees.v10i1.56275 compared to the distribution of lithologies, porosity, and hydrocarbon-bearing reservoir rock indicated by well logs (Lake, 2012)

Petrophysical parameter studies are fundamental for well development and production, as well as for estimating hydrocarbon reserves in any gas field (Islam et al., 2014). The determination of reservoir quality largely depends on the quantitative evaluation of petrophysical properties (Islam et al., 2006). Petrophysical studies include lithology, porosity, permeability, and hydrocarbon saturation assessments (Sakurai et al., 2002). Previously, some researches were conducted on petrophysical assessments utilizing well logs to evaluate the reservoir quality of some gas fields of Bangladesh (Abdullah Al Fatta et al.; Ahammod et al., 2014; Hai et al., 2014; Hossain et al., 2015; Hossain et al., 2021; Islam et al., 2013; Islam et al., 2014; Islam et al., 2006; Johnson and NUR ALAM, 1991; Samad et al., 2014; Shofiqul and Nusrat, 2013). These previous researches were prompted by the fact that Bangladesh's gas-bearing reservoirs were given considerable attention due to their economic significance. 
Habiganj gas field is Bangladesh's second most productive gas field in terms of GIIP (Gas Initially in Place) and third in terms of production, after Titas and Bibiyana Gas Fields. The $1^{\text {st }}$ well 'Habiganj-1' was drilled in 1963. Till 2007, 11 wells have been drilled at this gas field in total. Now 8 wells are in production. The GIIP of this field was measured at $3684.0 \mathrm{Bcf}$. Of this, proved (1P) is $2647.0 \mathrm{Bcf}$, proved + probable $(2 \mathrm{P})$ is also $2647.0 \mathrm{Bcf}$ and proved + probable + possible (3P) is $3096.0 \mathrm{Bcf}$ in amount. The cumulative production of this field is $2506.84 \mathrm{Bcf}$ till 2019 (Petrobangla, 2019). The remaining reserve is calculated as $140.16 \mathrm{Bcf}$ ( $1^{\text {st }}$ January 2020$)$. So, this gas field can be considered as its matured stage and at this time, reserve re-estimation, as well as reevaluation, is important for further development of this field. However, no detailed research is done so far for reevaluation and reappraisal of this field. Few studies have been conducted on reserve re-estimation and characterization particularly on Habiganj Gas Field but those are based on few selected wells of the field where one reservoir zone had been considered (Rahman et al., 2017; Shofiqul and Nusrat, 2013). Thus, it is mandatory to do a research including all the wells of Habiganj gas field to detect all possible reservoir zones for a detailed reservoir scenario of the field. We have therefore considered conducting this research as a comprehensive study on petrophysical parameters and reservoir characterization, the prerequisites for reservoir evaluation.
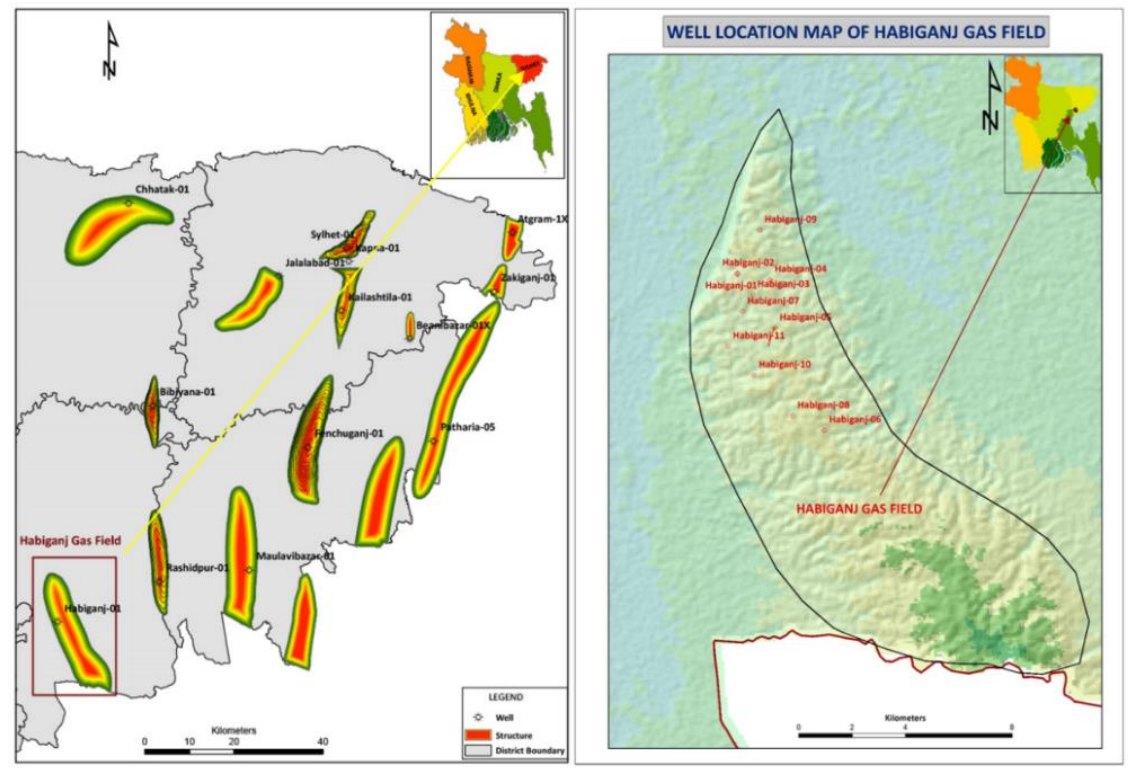

Figure 1: Habiganj Gas Field and Nearby Gas Fields of Surma Basin, Bangladesh are shown on the Map (left). Well Locations are shown on a Map (right) 


\section{DATA AND METHODS}

To achieve the objectives of the present study, necessary geophysical well log data have been collected from the Bangladesh Oil, Gas and Mineral Corporation (Petrobangla) authority and used with proper permission. The $\log$ data of 11 wells of Habiganj Gas Field include caliper, gamma-ray (GR), resistivity (deep \& shallow), density (RHOB), neutron porosity (NPHI) logs. Petrel software was used to analyze the well log data. The methodology follows an analytical approach (Figure 2). Empirical equations are applied to estimate the petrophysical properties of reservoir units delineated on the well logs.

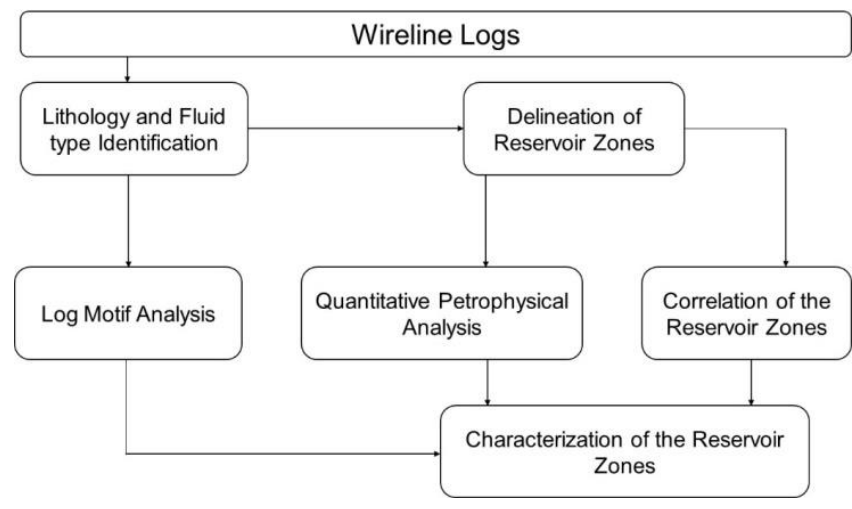

Figure 2: Workflow Showing the Different Analysis Performed in this Research

\section{Lithology Identification}

Lithology has been identified with the help of Gamma-ray log responses in the study wells. A low gamma value indicates sand and a high gamma value indicates shale. Lithology identification is also crosschecked from neutron-density cross plots.

\section{Reservoir Zones Identification}

The hydrocarbon-bearing zones of the shale-sand sequence are identified with the help of composite log responses. Conventional Gamma Ray, resistivity (deep $\&$ shallow), neutron $\&$ density $\operatorname{logs}$ of a total of 11 wells of Habiganj Gas Field are targeted to identify hydrocarbon-bearing zones (Table 1). Caliper log is also observed to supplement the identification of gas-bearing zones.

\section{Well Correlation}

The sand/shale curves show several distinguishable sedimentary cycles and also indicate the presence of sedimentary breaks and unconformities, which form the basis of correlation. Correlation is based on the lithology and interpretation of well logs. Mainly, the Gamma Ray log which is known as facies log has been used as the prior tool to correlate.

\section{Shale Volume Calculation}

To estimate the shaliness in the reserorvoir zones of Habiganj Gas Field, natural gamma-ray (GR) log is used. (Hussain et al., 2017) The clean sand or minimum gamma-ray and shale value or maximum gamma-ray are chosen for each zone for shale volume evaluation by observing the gamma-ray log.

Dresser Atlas equation (Dresser Atlas, 1979) has been used to calculate shale volume (Vclay) is:

$$
\text { Vclay }=(\text { GRlog }- \text { GRmin }) /(\text { GRmax }- \text { GRmin })
$$

Here, GRlog is the log derived value, and GRmin and GRmax indicated the minimum and maximum values of gamma-ray found from the log, respectively.

Table 1: List of the Wells with Available Wireline Log Data Utilized in this Research

\begin{tabular}{|l|c|c|c|c|c|c|c|c|c|}
\hline Well No. & GR & Caliper & MSFL & ILD & LLD & SFLU & NPHI & RHOB & Sonic \\
\hline Habiganj 1 & $\checkmark$ & $\checkmark$ & $x$ & $\checkmark$ & $x$ & $\checkmark$ & $\checkmark$ & $\checkmark$ & $\checkmark$ \\
\hline Habiganj 2 & $\checkmark$ & $\checkmark$ & $x$ & $\checkmark$ & $x$ & $\checkmark$ & $\checkmark$ & $\checkmark$ & $\checkmark$ \\
\hline Habiganj 3 & $\checkmark$ & $\checkmark$ & $x$ & $\checkmark$ & $x$ & $\checkmark$ & $\checkmark$ & $\checkmark$ & $x$ \\
\hline Habiganj 4 & $\checkmark$ & $\checkmark$ & $\checkmark$ & $\checkmark$ & $x$ & $\checkmark$ & $\checkmark$ & $\checkmark$ & $x$ \\
\hline Habiganj 5 & $\checkmark$ & $\checkmark$ & $x$ & $\checkmark$ & $x$ & $\checkmark$ & $\checkmark$ & $\checkmark$ & ----- \\
\hline Habiganj 6 & $\checkmark$ & $\checkmark$ & $x$ & $\checkmark$ & $x$ & $\checkmark$ & $\checkmark$ & $\checkmark$ & $x$ \\
\hline Habiganj 7 & $\checkmark$ & $\checkmark$ & $\checkmark$ & $\checkmark$ & $x$ & $\checkmark$ & $\checkmark$ & $\checkmark$ & ----- \\
\hline Habiganj 8 & $\checkmark$ & $\checkmark$ & $x$ & $\checkmark$ & $x$ & $\checkmark$ & $\checkmark$ & $\checkmark$ & $x$ \\
\hline Habiganj 9 & $\checkmark$ & $\checkmark$ & $x$ & $\checkmark$ & $x$ & $\checkmark$ & $\checkmark$ & $\checkmark$ & $x$ \\
\hline Habiganj 10 & $\checkmark$ & $\checkmark$ & $\checkmark$ & $\checkmark$ & $x$ & $\checkmark$ & $\checkmark$ & $\checkmark$ & ----- \\
\hline Habiganj 11 & $\checkmark$ & $\checkmark$ & $\checkmark$ & $\checkmark$ & $x$ & $\checkmark$ & $\checkmark$ & $\checkmark$ & ----- \\
\hline
\end{tabular}

[Explanation: $\checkmark=$ This $\log$ data has been used, $x=$ This log data was available but not used, ---- $=$ This log data was unavailable. 
This is further corrected by using the following equation (Clavier et al., 1971):

$$
V c l-c o r r=(1.7-\sqrt{ }(3.38-V c l+0.7) 2)
$$

The end result of the shale volume is estimated for each point.

\section{Porosity Calculation}

Effective porosity indicates the porosity available to free fluids in any reservoir (Islam Miah, 2014). In the present research both neutron log and density log have been used to measure the effective porosity of the reservoir zones. Firstly, clay corrected porosity of neutron $\log$ and density log have been measured using particular equations.

The clay corrected porosity of neutron $\log$ is calculated by the following equation (Asquith et al., 2004):

$\Phi n-\operatorname{corr}=N P H I-(V c l-\operatorname{corr} X \Phi n-c l)+$ lithology correction

Where $\Phi_{\text {n-cl }}$ is the neutron porosity estimated from a pure shale zone from the respective logs, NPHI is the log values for neutron porosity log and lithology correction is $0.04 \%$.

Again, the clay corrected density is measured using the equation below (Bassiouni, 1994):

$$
\begin{aligned}
& \Phi d-\operatorname{cor}=(\text { RHOBmax }- \text { RHOBcorr }) / \\
& (\text { RHOBmax }- \text { RHOBfl })
\end{aligned}
$$

For this equation, a default value of RHOBmax $=2.69$ and $\mathrm{RHOBfl}=1$ have been used.

Finally, the values of neutron and density porosity corrected for the presence of clays are used in the equation below to determine the effective porosity (Asquith et al., 2004):

$$
\Phi \text { eff }=\sqrt{ }\{(\Phi n-\operatorname{corr}) 2+(\Phi d-\text { corr }) 2\}
$$

\section{Water Saturation Calculation}

In this research, water saturation has been calculated by using the Simandoux Method (Simandoux, 1963):

$$
\begin{aligned}
S w=\{(0.4 x R w & /(\Phi e f f 2)\} \\
& *([\sqrt{ }\{(5 x(\Phi e f f) 2) /(R w X R t) \\
& +(\text { Vsh } / R s h) 2\}-(V s h / R s h])
\end{aligned}
$$

Here, $\mathrm{Sw}=$ water saturation; $\mathrm{C}=0.4$ (constant); $\mathrm{Rw}=$ resistivity of water; $\mathrm{Rt}=$ true resistivity and
Фeff = effective porosity. Hydrocarbon saturation is then determined from $(1-\mathrm{Sw})$.

\section{Permeability Calculation}

The permeability of sand bodies is calculated using the Wylie-Rose method. This method includes the following equations (Crain, 1986):

$$
\begin{aligned}
& \text { Swir }=(\text { PHI } x \text { Sw }) / \text { PHIe } \\
& K=6500 \times\left(\frac{\text { PHIeff } 6}{\text { Swir4.6 }}\right)
\end{aligned}
$$

In the first equation, PHI represents the value from the $\log$ and PHIe is the value of effective porosity. 6500 is a constant used in calculating permeability.

Finally, the results are obtained by applying the above-described quantitative workflow.

\section{RESULTS}

From well log analysis, two main reservoir zones have been identified in Habiganj Gas Field. The upper reservoir zone has been found all through the eleven wells of the field (well locations shown in Figure 1). Though the overall thickness of upper reservoir zones varies, apparently this zone is penetrated around at $1316 \mathrm{~m}$ depth (HB-7) and extended till 1733m depth (HB-3). But in the lower reservoir zone, there is lateral discontinuity. The lower reservoir zone is only found in 4 wells of the field (HB-1,5,7 and 11) at a depth ranging between $3025 \mathrm{~m}$ (HB-1) to $3245 \mathrm{~m}$ (HB5). This lower reservoir zone is also vertically discontinuous interbedded with shale layers. Gas water contacts have been identified from the log (resistivity $\log$ ) which are mostly at depth of around $1486 \mathrm{~m}$ (SSTVD) in most of the wells (HB$3,4,5,7,8,10$ and 11). In HB-1, gas-water contact is identified at depth of $1488 \mathrm{~m}$, in HB-2,9 it is found at $1415 \mathrm{~m}$ and in HB-6 this contact is found at $1475 \mathrm{~m}$ depth. Stratigraphically upper reservoir zone is situated in Bokabil formation and the lower reservoir zone is in Bhuban formation.

The lithology of the reservoir zones has been identified from gamma-ray (GR) $\log$ and neutrondensity cross plots. The GR $\log$ is used to trace clean (shale-free) sandstones vs. shaly sandstones and carbonates. Shale exhibits relatively high GR count rates due to the presence of radioactive minerals in their composition. On the other hand, reservoir rock (composed mainly of quartz, calcite, dolomite, etc.) exhibits relatively low gamma-ray count rates 
(Merkel, 1979). From the gamma-ray log, the lithology of HB wells is found with API values ranging from an average of $60-80$ for sand and 120140 for shale (Figure 3a). Also, a cross-plot between density-neutron porosity log data from the $\mathrm{HB}$ wells is done to identify lithology (shown for HB-11 in Figure 3b). This cross-plot is commonly used to differentiate between reservoir rocks, such as sandstone, limestone, and dolomite, and shale and some evaporate (Abdullah Al Fatta et al.). The cross-plots generated for $\mathrm{HB}$ wells, clearly differentiate the gas sand, brine sand, and shale (Figure 3b).

Shale has a significant impact on reservoir quality. Therefore, estimation of shale volume is very important in reservoir characterization. From log analyses, it has been seen that the shale volume of the upper reservoir zone ranges from $9 \%$ to $23 \%$ with an average of $13 \%$. In the lower reservoir zone, the range is from $14 \%$ to $28 \%$ with an average clay content of $21 \%$.

Two hydrocarbon-bearing zones are identified with the aid of resistivity (deep resistivity $\log$ (ILD) and shallow resistivity log (MSFL)), gamma-ray, neutron, and density logs. The hydrocarbon contents and types of these reservoir zones are detected by high values of resistivity (> 1000 ohm.m), low values of gamma-ray (60-80 API), low density (avg. $2.2 \mathrm{~g} / \mathrm{cc}$ ), and high neutron $\log$ (avg. $0.20 \mathrm{~m} 3 / \mathrm{m} 3$ ) responses. The separation between the neutron and density curves shown by $\log$ responses are distinguishing characteristics of hydrocarbons. In neutron-density combination, gas has stood out distinctly, giving a large negative separation as neutron log measures low porosity due to the presence of gas. Higher true resistivity responses of these zones compared to lower water resistivity responses, and vice versa, also suggest that the hydrocarbon type is gas carrying. Graphical representation of composite log response of HB-10 \& HB-11 wells are shown in Figure 4. Other wells' reservoir zones are identified similarly.

The combination of the neutron and density measurements is one of the widely used porosity log combinations. The response of the combination is such that for reconnaissance evaluation one can forego the cross plot and rely on recognition of the curve patterns to quickly determine the most likely predominant lithology and formation porosity (Asquith et al., 2004). Therefore, porosity has been calculated using neutron-density formulae.

Porosity value ranges from $12 \%$ to $36 \%$ in the upper reservoir zone with an average of $28 \%$ (Figure 5 ). In the lower reservoir zone, the average porosity values of $18.44 \%, 16.71 \%$, and $13.11 \%$ are estimated in HB-1, 7 \& 11 no. wells, respectively. The porosity distribution ranging from $4 \%$ to $24 \%$ in lower reservoir zones with a peak at $10 \%$ can be seen in the histogram (Figure 5).

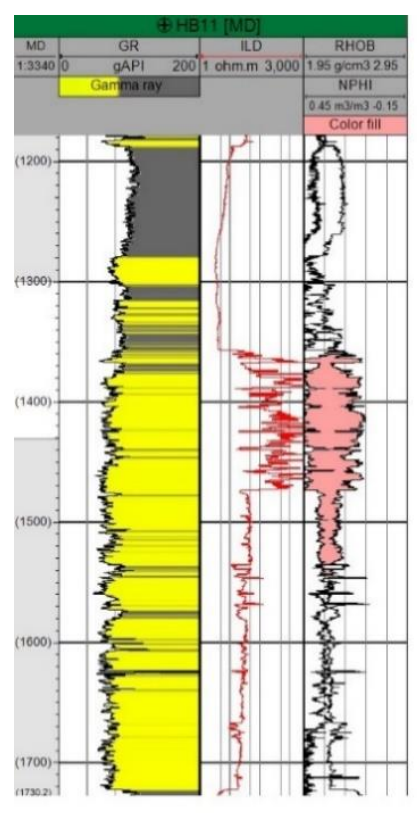

a

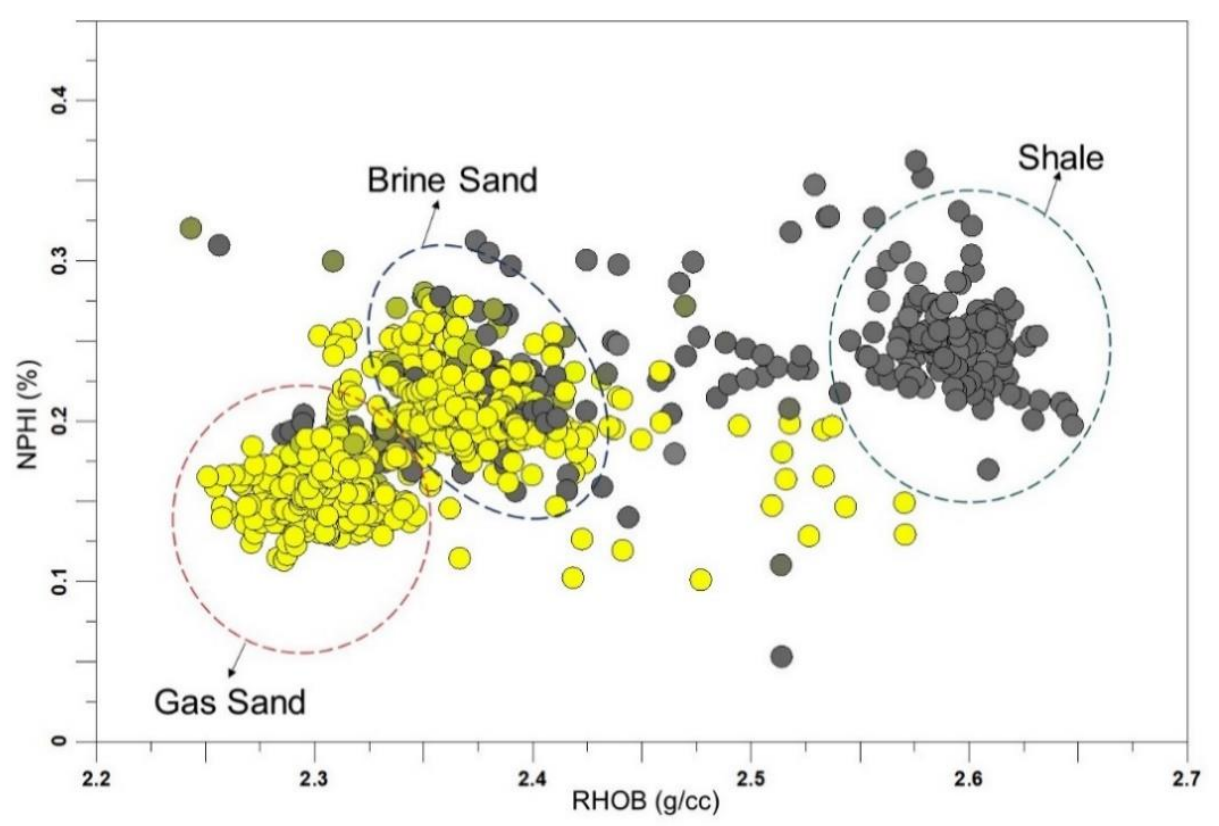

b 
Figure 3: Log Plot and a Cross Plot Showing Different Lithologies and Fluid Types

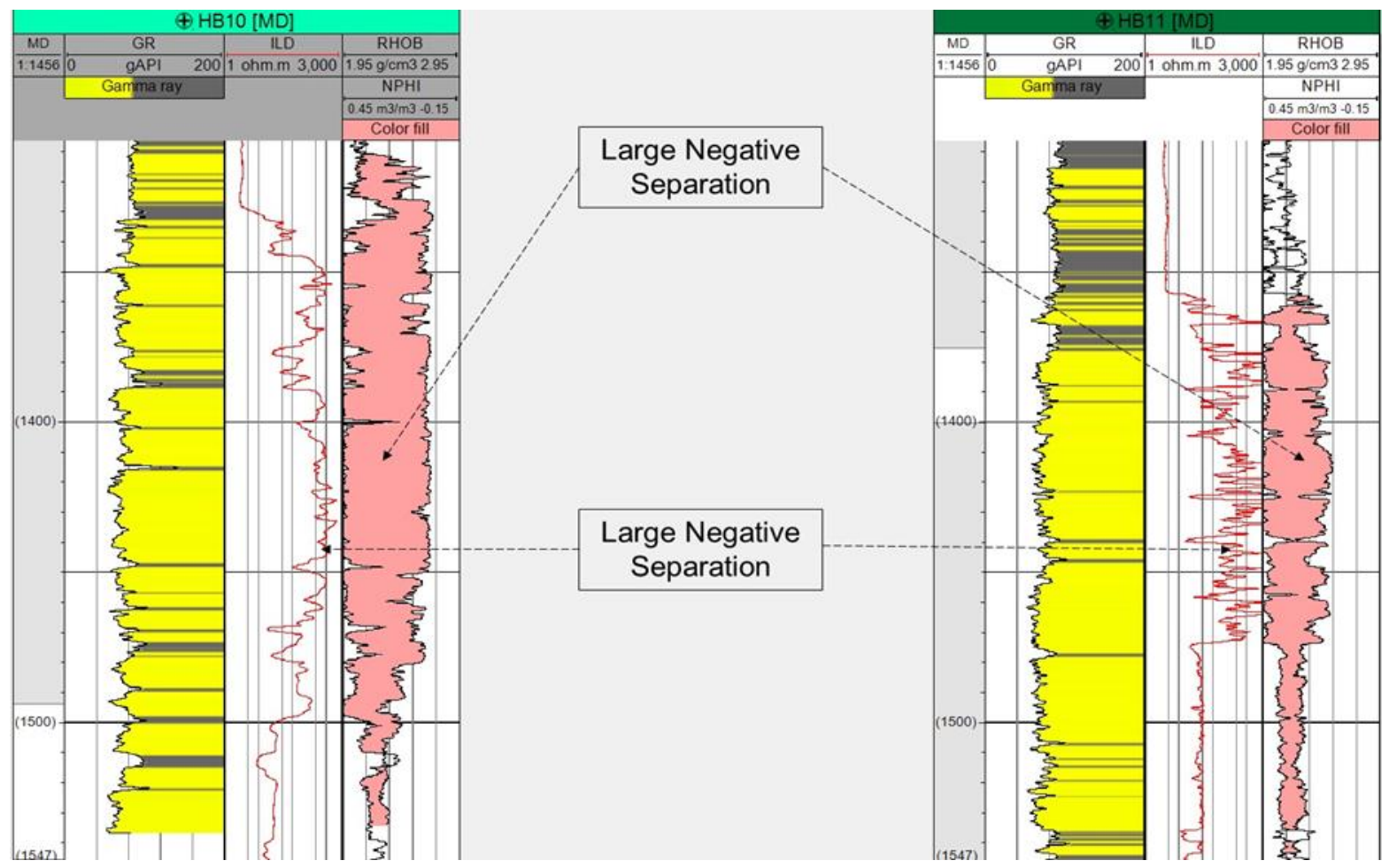

Figure 4: Large Negative Separation and High Resistivity Values in Low Gamma-ray Intervals Indicate the Presence of Hydrocarbon
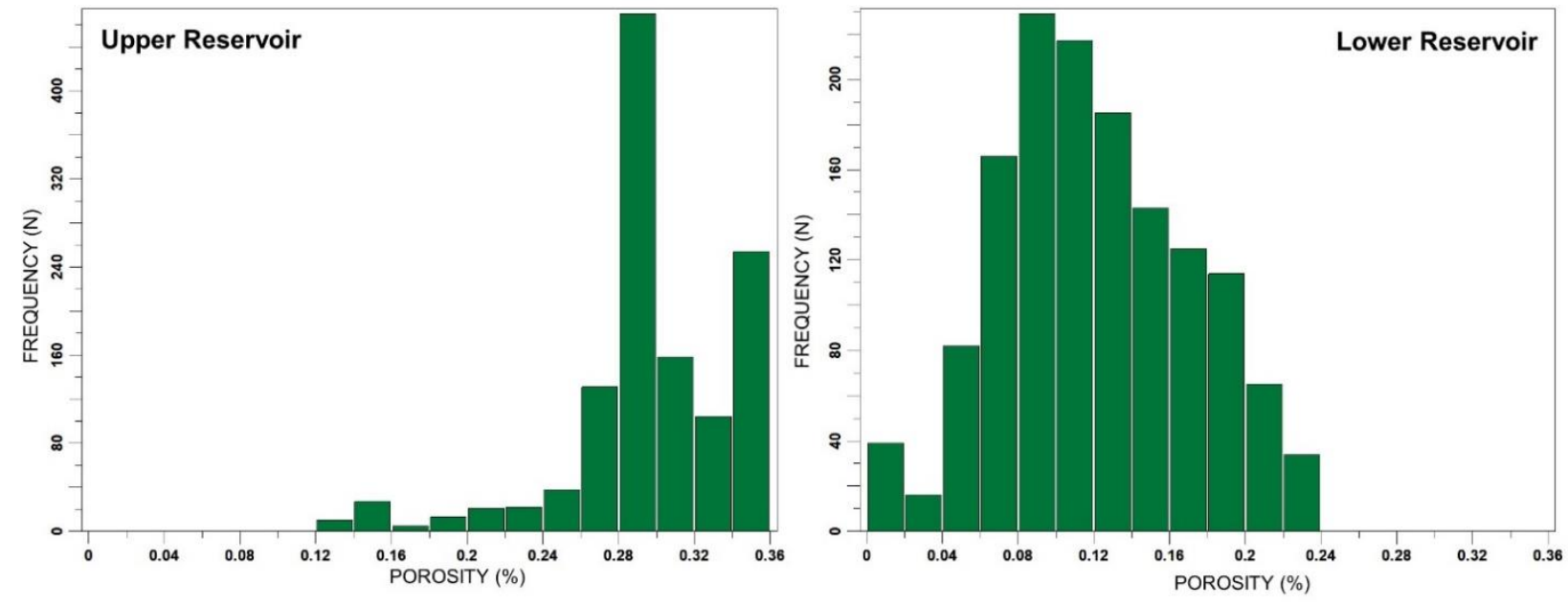

Figure 5: Histograms Showing Porosity Distribution in Upper and Lower Reservoirs

The permeability is a primary reservoir property that defines the access of fluid movement within the reservoir. It is the most difficult property to determine and predict (Singh, 2019). A generalized equation was given by Wyllie and Rose (1950) to estimate the intrinsic permeability of the rocks by using effective porosity and the irreducible water saturation (Cetin, 2016) which is used in this study to calculate the permeability. Permeability value is found ranging from $100 \mathrm{mD}$ to 2 Darcy in the upper reservoir of Habiganj Gas Field with an average of around $500 \mathrm{mD}$. But in the lower reservoir zone, the permeability value is not consistent in all the wells. The histogram shows permeability distribution ranging from $20 \mathrm{mD}$ to $300 \mathrm{mD}$ with a peak at $60 \mathrm{mD}$ (Figure 6).

The amount of water saturation of the reservoir zones is calculated using the Simandoux equation 
(1963) instead of Archie's equation (Archie, 1942) as Archie's original equation is based on clean sandstones reservoir. The presence of shale causes disparity in the reading of total resistivity of the reservoir and brings about an overshot in the water saturation predicted by Archie's equation (Archie, 1942; Sam-Marcus et al., 2018). Therefore, the Simandoux equation is chosen for this study to take into account the effect of shale on overall resistivity as well as on the water saturation value of the reservoir zones. Water saturation value is found around $10 \%$ to $60 \%$ in upper reservoir zones and in lower reservoir zones it ranges from $60 \%$ to almost $90 \%$ (Figure 7). Hydrocarbon saturation is calculated as 1 minus water saturation (1- Sw) (Abdullah $\mathrm{Al}$ Fatta et al.). By this, hydrocarbon saturation is estimated as high as $90 \%$ in the upper reservoir zone. In the lower reservoir zone, hydrocarbon saturation ranges around $10 \%$ to $50 \%$.
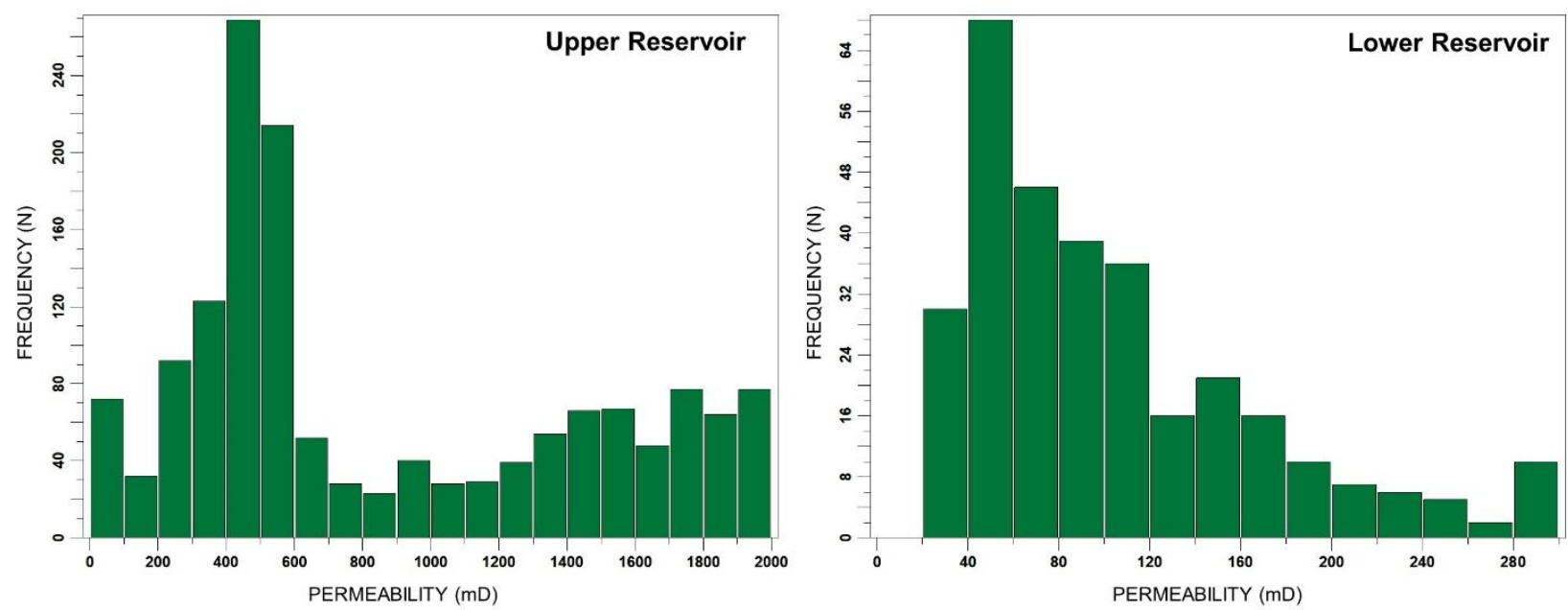

Figure 6: Histograms Showing Permeability Distribution in Upper and Lower Reservoirs
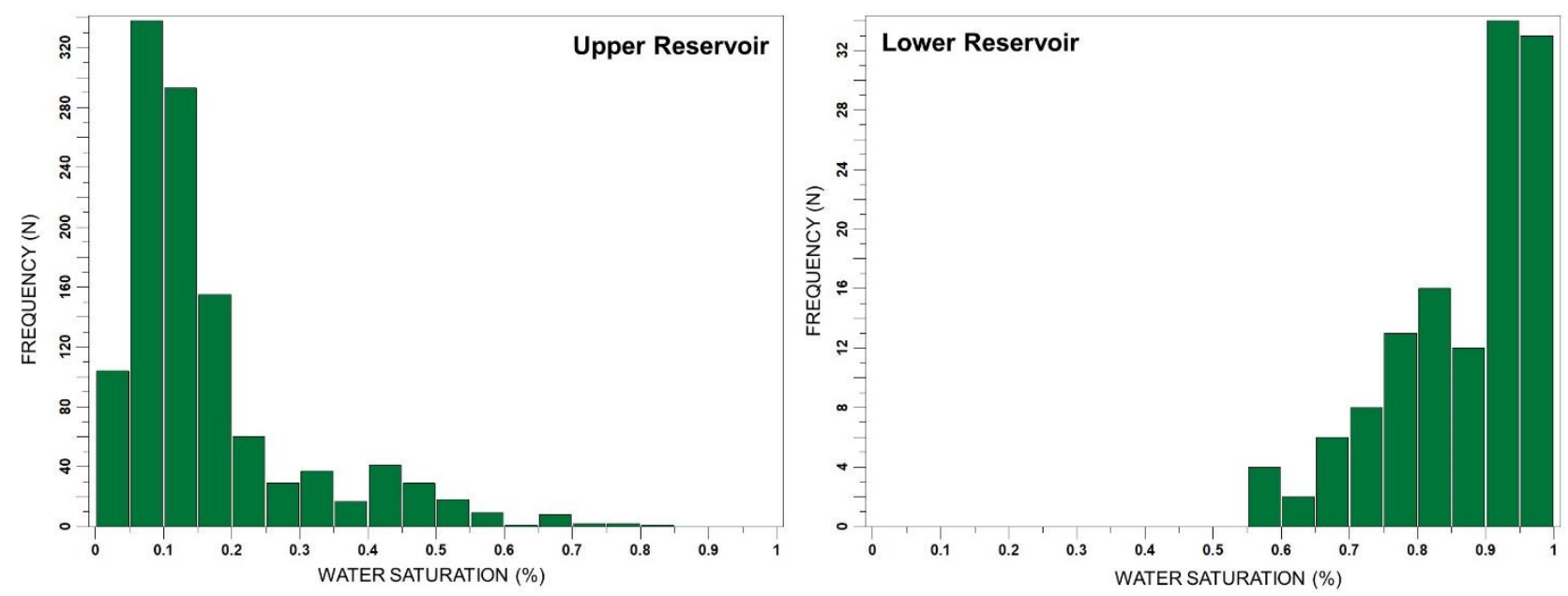

Figure 7: Histograms Showing Water Saturation Distribution in Upper and Lower Reservoirs
Well correlation is also performed to study the variation in reservoir thickness, continuity and connectivity. A cross section panel in N-S direction is prepared for each zone. Correlation of upper reservoir zone shows the presence of this zone on all the 11 wells in Habiganj field. Net pay thickness of this zone is also quite consistent with no significant variation. The highest thickness is observed in HB-7 (350m (TVD)) and the lowest in HB-2 (144m (TVD)).

The sands in this interval are very consistent in terms of gamma-ray character and the log motif. Sands are stacked in a blocky pattern with minor silt and clay separating them. The silt and clay layers are not laterally continuous. Thus they have no effect on the reservoir connectivity as well as no significant control on the lateral and vertical variation in reservoir properties in field scale. 


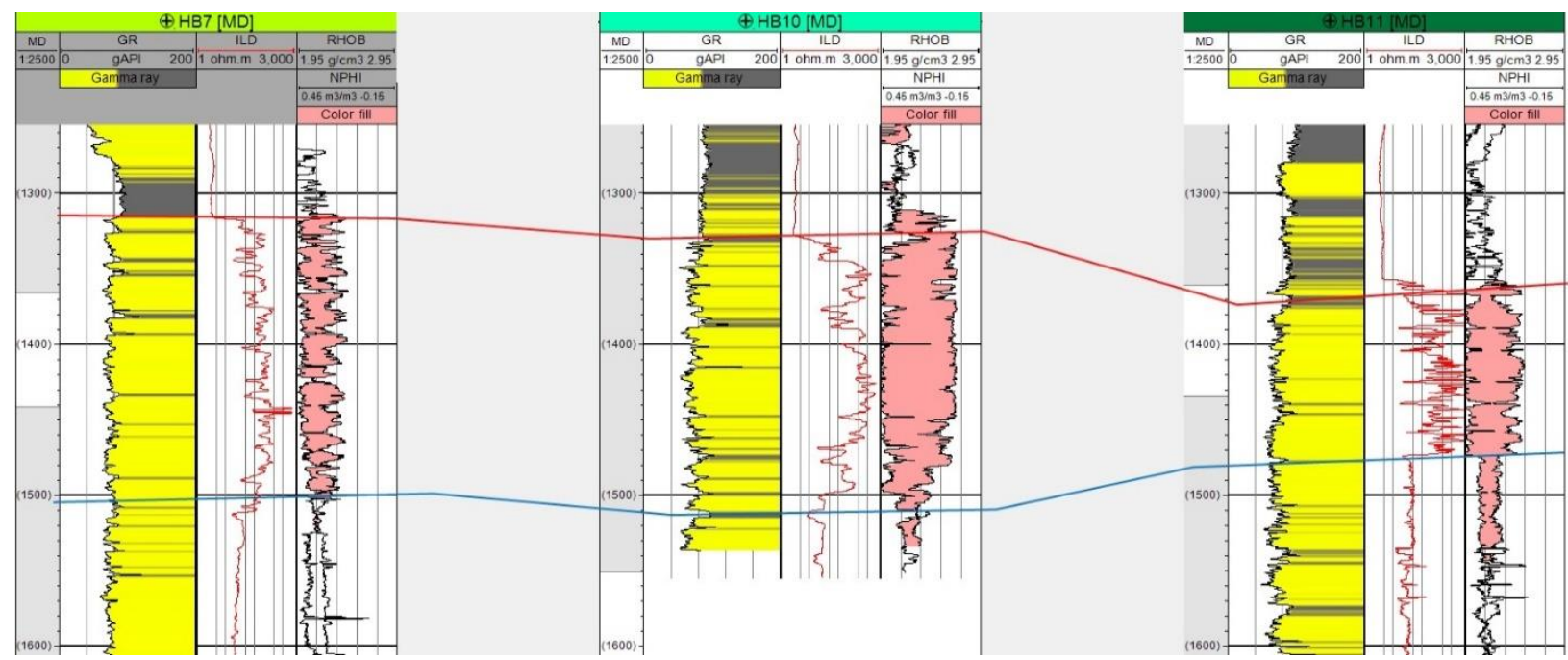

Figure 8: Correlation of Upper Reservoir Zone in an N-S Cross-section

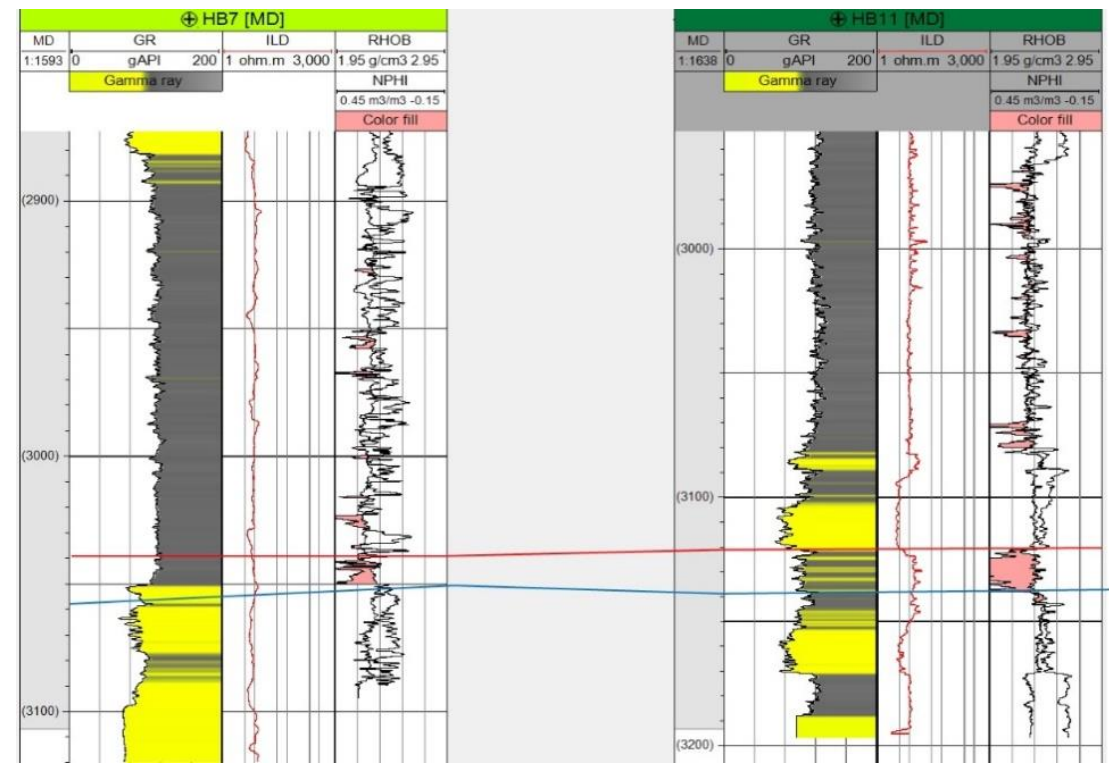

Figure 9: Correlation of the Lower Reservoir Zone in an N-S Cross-section

The well correlation of the lower reservoir zone shows sands are not laterally continuous and cannot be correlated across more than 3 wells. The lower reservoir zone is shale-dominated and the sands show a serrated pattern. Thick shale zones will affect the lateral and vertical distribution and reservoir properties. Compared to the upper reservoir zone sands in this interval is not clean as evident by the higher gamma-ray value. This and the serrated pattern suggest sands in this interval have significant shale interspersed within the sand layers.

\section{DISCUSSION}

This study reveals that there are two reservoir zones in Habiganj Gas Field penetrating Bokabil and
Bhuban Formations. Based on the results, it is observed that the upper reservoir zone has an enormous thickness (avg. around $230 \mathrm{~m}$ ) with high porosity and permeability values (avg. $28 \%$ and $500 \mathrm{mD}$ ) and very low shale volume (avg. 13\%) which make this zone a very good quality reservoir. In the case of the lower reservoir zone, the porosity, permeability values are found relatively low (avg. 10\% and 60mD), also the volume of shale is higher (avg. 21\%) than the upper reservoir zone and this lower zone is very thin (around $14 \mathrm{~m}$ ) which deteriorate the reservoir quality compared to the upper zone. It is evident that the reservoir quality varies in both zones, and this might be related to varying depositional conditions. These two reservoir zones are stratigraphically part of the Surma Group 
(Imam, 2005). Traditionally, Surma Group units are believed to be deposited in fluvio-deltaic to shallow marine environments (Johnson and Alam, 1991; Merkel, 1979). It is evident from log analysis that the upper reservoir zone contains a thicker sand body with a minor interbedded shale-silty lithology that does not affect reservoir continuity and connectivity. This laterally continuous stacked clean sand body with high poro-perm values is also indicative of the high energy condition of the deposits which might be braided fluvial system (Asquith et al., 2004; Singh, 2019). The lower gas sands are less porous and more clay plugged than the upper gas sand in the Habiganj field indicating that they belong to a lower depositional regime which might be delta front to offshore marine bar deposits. The laterally discontinuous nature of the lower gas sands is further proof of their marine depositional regime as compared to that of the Upper Gas Sand.

The resulting petrophysical properties indicate that an enhanced production might be favorable with a little development and/or appraisal efforts in the upper reservoir zone of Habiganj Gas Field. Although the reservoir quality of the lower zone of the Habiganj gas field is poorer than that of the upper zone, this part can be considered as the secondary target for hydrocarbon production.

However, this result and interpretation are based on wireline $\log$ data which are one-dimensional. The well log data sometimes fail to encompass the fieldwide variation of reservoir properties. And most petrophysical properties used in integrated studies are obtained through multiple workflows of the exploration-development portfolio, including data acquisition, processing, calibration, and interpretation. Each of these processes has uncertainties that may affect the result. Also, the equations that have been used for calculation may vary if some other equations were being used. Thus, it is suggested that core data of these wells and seismic data of Habiganj Gas Field should be incorporated with this study to allow for the detailed and complementary study of the field which will reduce inherent uncertainties.

\section{CONCLUSION}

Through the present study, we attempt to comprehend the nature and potentiality of the Habiganj Gas Field using wireline logs of all the 11 wells of this field. Lithology and reservoir zones are identified directly from the log. Effective porosity, permeability, shale volume, and water saturation are measured using relevant petrophysical equations. From the calculation, it has been found out that the average porosity of the upper reservoir zones is $28 \%$, average permeability is around $500 \mathrm{mD}$ with hydrocarbon saturation values ranging from $40 \%$ to $90 \%$. The average volume of shale is found at $13 \%$ in the upper reservoir zone. And in lower reservoir zones the average porosity value is around $10 \%$, permeability value is not consistent in all wells but in the average value of $60 \mathrm{mD}$, hydrocarbon saturation is relatively low ranging from $10 \%$ to $50 \%$. The average volume of shale is $21 \%$ within this lower reservoir. Based on the petrophysical analyses, it could be concluded that the upper reservoir zone is a very good quality reservoir and the lower reservoir zone is also potential. The variation between two reservoir zones might be due to different depositional environments. The upper reservoir zone is assumed to be deposited in high energy conditions and the lower reservoir zone might be deposited in lower energy conditions. The lower reservoir should be studied more rigorously with other associated data to reveal its precise potentiality. However, this study indicates that the Habiganj Gas Field is a very prospective area in terms of yet to find hydrocarbons and for further development. These findings may help in the reestimation of gas reserves and may also help to add reserves to our national gas reserve bucket.

Acknowledgement: The authors are grateful to the Bangladesh Oil, Gas, and Mineral Corporation (Petrobangla) for their kind permission, cooperation and access to the relevant data required for this study. The authors are also grateful to $M$. A. Matin Mondol, manager at BAPEX's geophysical division, for helping to prepare some illustrations for this research paper.

\section{REFERENCES}

Abdullah Al Fatta, M., Islam, S., and Farhaduzzaman, M. (2018). Petrophysical Analysis of Sylhet Gas Field Using Well Logs and Associated Data from Well Sylhet, Bangladesh. International Journal of Petroleum and Petrochemical Engineering, 4(1): 55-69, DOI: http://dx.doi.org/10.20431/2454-7980.0401007.

Ahammod, S., Hai, M. A., Islam, M. R., and Abu, S. (2014). Petro-Physical Analysis of Reservoir Rock of Fenchuganj Gas Field (Well\# 03) Using Wireline Log: American Journal of Engineering Research, Vol. 3(8):37-48

Archie, G. E. (1942). The electrical resistivity log as an aid in determining some reservoir characteristics: Transactions of the AIME, 146 (1):54-62. 
Asquith, G. B., Krygowski, D., and Gibson, C. R. (2006). Basic well $\log$ analysis, American Association of Petroleum Geologists Tulsa: p. 244.

Dresser Atlas (1979). Log interpretation charts: Houston Dresser Industries: Inc, p. 107.

Bassiouni, Z. (1994). Theory, measurement, and interpretation of well logs, Henry L. Doherty Memorial Fund of AIME, Society of Petroleum Engineers. 4, SPE textbook series

Bateman, R., 1985, Openhole log analysis and formation analysis. United States: N. p., 1985.

Cetin, M. (2016). A petrophysical evaluation for permeability of a gas reservoir in the Taranaki Basin, New Zealand: Michigan Technological University.

Clavier, C., Hoyle, W., and Meunier, D. (1971). Quantitative interpretation of thermal neutron decay time logs: part I. Fundamentals and techniques: Journal of Petroleum Technology, 23(6): 743-755.

Crain, E. R. (1986). Log analysis handbook. United States: N. p., 1986.

Hai, M. A., Ahammod, S., Faruque, M. O., Hussain, M. A., and Ahmed, J. (2014). Identification and determination of gross thickness of hydrocarbon bearing zone of Habiganj gas field: Am J Engg Res, 3(8):79-89.

Hossain, A., Hossain, D., and Abdullah, R., 2015, Structural and stratigraphic interpretation of geophysical data of the Fenchuganj gas field in the Surma basin, Bangladesh: Journal of the Geological Society of India, 86 (2):148-154.

Hossain, M. I. S., Woobaidullah, A., and Rahman, M. J., (2021). Reservoir characterization and identification of new prospect in Srikail gas field using wireline and seismic data: Journal of Petroleum Exploration and Production Technology, 11: 2481-2495

Hussain, M., Ahmed, N., Chun, W. Y., Khalid, P., Mahmood, A., Ahmad, S. R., and Rasool, U. (2017). Reservoir characterization of basal sand zone of lower Goru Formation by petrophysical studies of geophysical logs: Journal of the Geological Society of India, 89 (3):331-338.

Imam, B. (2005). Energy Resources of Bangladesh: University grants commission of Bangladesh, Dhaka.

Islam, A., Habib, M., Islam, M., and Mita, M. (2013). Interpretation of wireline $\log$ data for reservoir characterization of the Rashidpur Gas Field, Bengal Basin, Bangladesh: IOSR Journal of Applied Geology and Geophysics, 1(4): 47-54.

Islam, A., Islam, M. A., Tasnuva, A., Biswas, R. K., and Jahan, K. (2014). Petrophysical parameter studies for characterization of gas reservoir of Narsingdi gas field,
Bangladesh: International Journal of Advanced Geosciences, 2(2):53-58.

Islam, M. A., Islam, M., Latif, M., Mondal, D., and Mahbub, M. (2006). Petrophysical analysis of shalysand gas reservoir of Titas Gas Field using well logs: Bangladesh, Journal of Geology, 25: 106-124.

Islam Miah, M. (2014). Formation evaluation using wireline log data of Bakhrabad gas field. http:/ /lib.buet.ac.bd: 8080 / xmlui/ handle/ 123456789/1460.

Johnson, S. Y., and Alam, A. M.N. (1991). Sedimentation and tectonics of the Sylhet trough, Bangladesh: Geological Society of America Bulletin, 103(11):15131527.

Lake, L. (2012). Reservoir characterization, Elsevier.

Merkel, R. H. (1979). Well log formation evaluation, United States: DOI: https://doi.org/ 10.1306/ CE14453

Petrobangla (2019). Petrobangla Annual Report, 2019.

Rahman, A., Seddique, A. A., Khan, M. H. R., and Rahman, M. (2017). Present gas reserve estimation using wireline logging data of Habiganj Gas Field, Bangladesh: Int $J$ Oil Gas Coal Eng, 5 (4): 44-50.

Sakurai, S., Grimaldo-Suarez, F. M., Aguilera-Gomez, L. E., Rodriguez-Larios, J. A., Ambrose, W. A., Jennette, D. C., Holtz, M. H., Dutton, S. P., Wawrzyniec, T. F., and Guevara, E. H. (2002). Petrophysical evaluation of Miocene-Pliocene gas reservoirs: Veracruz and Macuspana Basins, Mexico, in Proceedings SPWLA $43^{\text {rd }}$ Annual Logging Symposium.

Sam-Marcus, J., Enaworu, E., Rotimi, O. J., and Seteyeobot, I. (2018). A proposed solution to the determination of water saturation: using a modelled equation: Journal of Petroleum Exploration and Production Technology, 8(4): 1009-1015.

Samad, M. A., Rahman, M. J., and Woobaidullah, A. (2014). Reservoir characterization of different gas fields in eastern fold belt of Bangladesh: Unpublished MS Thesis, University of Dhaka, Bangladesh.

Shofiqul, I. M., and Nusrat, J. L. (2013). Reservoir characterization of Habiganj gas field: International Journal of Oil, Gas and Coal Engineering, 1(1): 7-15.

Simandoux, P. (1963). Dielectric measurements on porous media, application to the measurements of water saturation: study of behavior of argillaceous formations: Revue de L'institut Francais du Petrole, 18: 193-215.

Singh, N. (2019). Permeability prediction from wireline logging and core data: a case study from AssamArakan basin: Journal of Petroleum Exploration and Production Technology, 9(1): 297-305. 